\title{
Pattern-Arrangements of Tobacco Shreds in the Internal Structure of Cigarettes*
}

\author{
by \\ Angel Nestorov and Chuon Vutby \\ Department of Tobacco and Tobacco Products Technology, \\ Higher Institute of Food and Flavour Industry, \\ Plovdiv, Bulgaria
}

\section{SUMMARY}

Analyses of indices observed in macro-photographs of a variety of cigarette cross-sections have shown that tobacco shreds forming the internal structure of cigarettes are highly arranged in a defined pattern in which their lenghts are predominantly oriented along the cigarette lenghts and their widths - parallel to the cigarette seams. These pattern-arrangements of tobacco shreds have an effect upon the dielectric properties and deformation of cigarettes. The deformation has been found to be bigger when measured perpendicular to seams.

\section{ZUSAMMENFASSUNG}

Kennwertanalysen in Makrophotographien von Cigarettendurchschnitten haben gezeigt, daß die Tabakstruktur von Cigaretten durch eine in hohem Maße festgelegte Anordnung der Tabakfasern bestimmt wird. Die Faserlänge verläuft hierbei überwiegend entlang der Cigarettenlänge, die Faserbreite parallel zur Klebenaht. Diese Struktur hat Auswirkungen auf die dielektrischen Eigenschaften und die Deformation. Es wurde festgestellt, daß Cigaretten senkrecht entlang der Klebenaht stärker deformiert sind.

* Received: 23rd January 1992 - accepted 24th August 1992.

\section{RESUME}

Une analyse de macrophotographies de sections transversales de cigarettes a montré que la distribution du tabac haché dans une cigarette est largement structurée, avec la longueur des brins de tabac suivant principalement la longueur des cigarettes et leur largeur étant parallèle aux coutures. Cet arrangement des brins de tabac influence les propriétés diélectriques des cigarettes ainsi que leur déformation. On a constaté que les cigarettes sont plus déformables perpendiculairement aux encollages.

\section{INTRODUCTION}

The internal cigarette structure has been the subject of a comparatively small number of investigations. GoLDRING, Fiore and Gadziala (1) have studied the arrangements of tobacco shreds in cigarettes applying macrophotography, longitudinal serial cross-sections and $\mathrm{X}$ radiography. They have come to the conclusion that tobacco shreds are arranged in a cigarette at random and there exist no recognizable structural differences beyond fluctuations in rod density. As yet this notion of cigarette structure has neither been confirmed nor rejected by further experimental data and is still accepted by other authors (2). 
Figure 1.

Electric condenser with arched electrodes with a cigarette placed between them. a) Seam in the middle of one of the electrodes; b) seam opposite to one of the gaps of the electrodes.
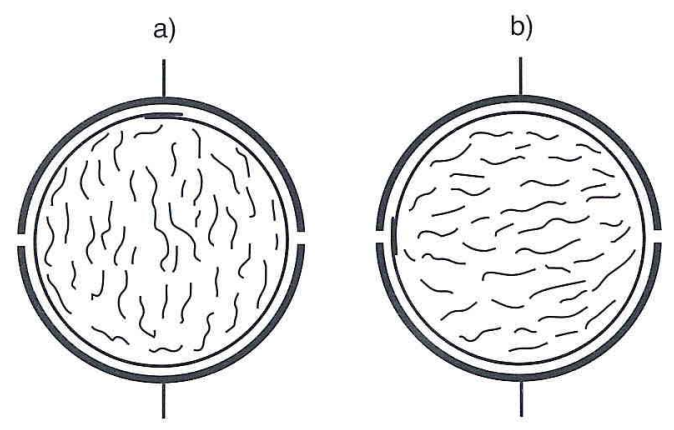

The reason why we started studies on cigarette structure were our observations of certain differences in the dielectric properties of cigarettes placed in a condenser with arched electrodes as shown in Figure 1. Quite a few observations indicated that the condenser capacity varied in relation to the cigarettes positions between the electrodes reaching its highest value when the cigarette seams faced the middle of one of the plates (Figure 1a), and its lowest value when the seams were in the zone of one of the gaps between the plates (Figure 1b). The assumption that such differences might be due to some influence exerted by the seam was rejected because the emptied cigarette wrappers placed in various positions showed no differences in the condenser capacity; hence our attention was focused on tobacco shred arrangements in cigarette cross-sections.

\section{EXPERIMENTAL}

The cigarette structure was analyzed by direct observations with the aid of a stereomicroscope and macrophotography. The cross-sections were made with a razor blade. The procedure is easy to perform requiring no special cutting instruments or fixing mixtures for embedding tobacco shreds, since the sections made with a new razor blade at tobacco moisture of $14 \%$ to $15 \%$ do not cause any particle losses or significant transposition of tobacco shreds. This was verified by the results obtained; nevertheless, to ensure uniformity of cutting conditions and facilitate the preparation of cross-sections a hand microtome was used (Figure 2).

The main part of the apparatus is a tube $(8 \mathrm{~mm}$ i.d.) where a cigarette is placed. On one end of the tube is mounted a device to push out the cigarette. It is composed of a nut and bolt ( $1 \mathrm{~mm}$ screw pitch) with a haft. Another device is mounted on the second end of the tube to restrict and direct the razor blade to make a cut perpendicular to the cigarette axis.

The visual stereomicroscopic observations were used for quality evaluation of the sections whereas macro-photography helped in analyzing and recording the results. From slides projected onto a screen, eightyfold enlarged drawings were made of the cigarette cross-sections outlining the contours of the cuts of each shred. The cuts were numbered in every picture.

\section{RESULTS AND DISCUSSION}

The tobacco shred cuts in cigarette cross-sections were of irregular shapes mostly a parallelopiped or an ellipse or a catenary with the two basic dimensions, lenght and width. In the cases of ribs cut, the cuts had enlarged sizes of the sections and arbitrary shapes. Straight lines as axes of symmetry were drawn along the length and width of the cut of each shred. Every cross-section was analyzed according to the following indices:

1. number of tobacco shreds within a cigarette crosssection;

2. length and width of tobacco shred cuts;

3. orientation of tobacco shred cuts in relation to the angle between the long axis of symmetry and the straight line tangential to the cigarette seam, here provisionally called "seam-line".

Figure 2.

Hand microtome.

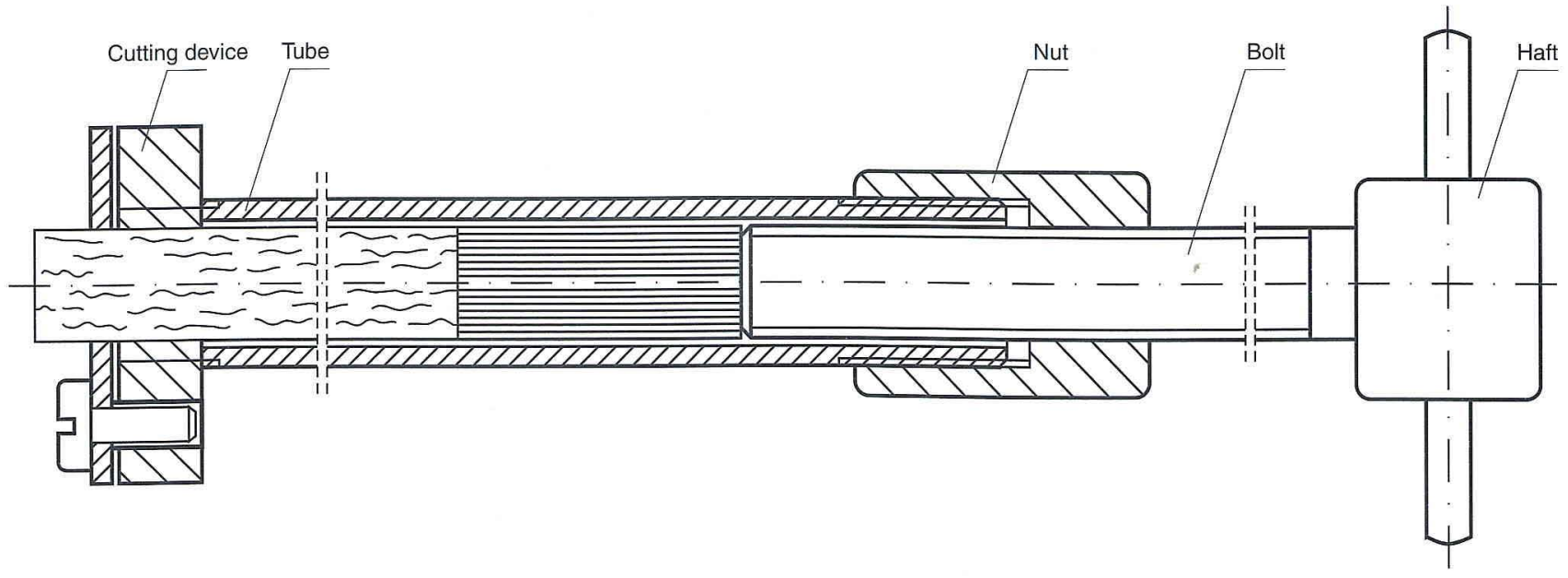


Figure 3 shows cross-sections of three cigarettes from different brands of which $\mathrm{A}$ and $\mathrm{B}$ are oriental blends and $C$ is an American blend. The position of the seam is marked with black ink on each cross-section. The cross- sections comprise different numbers of tobacco shred cuts: 110 for Cigarette A, 125 for Cigarette B and 101 for Cigarette C. It is not difficult to see cuts across a few ribs of different size and placement in each cross-section.

Figure 3a.

Cross-section of Cigarette A.

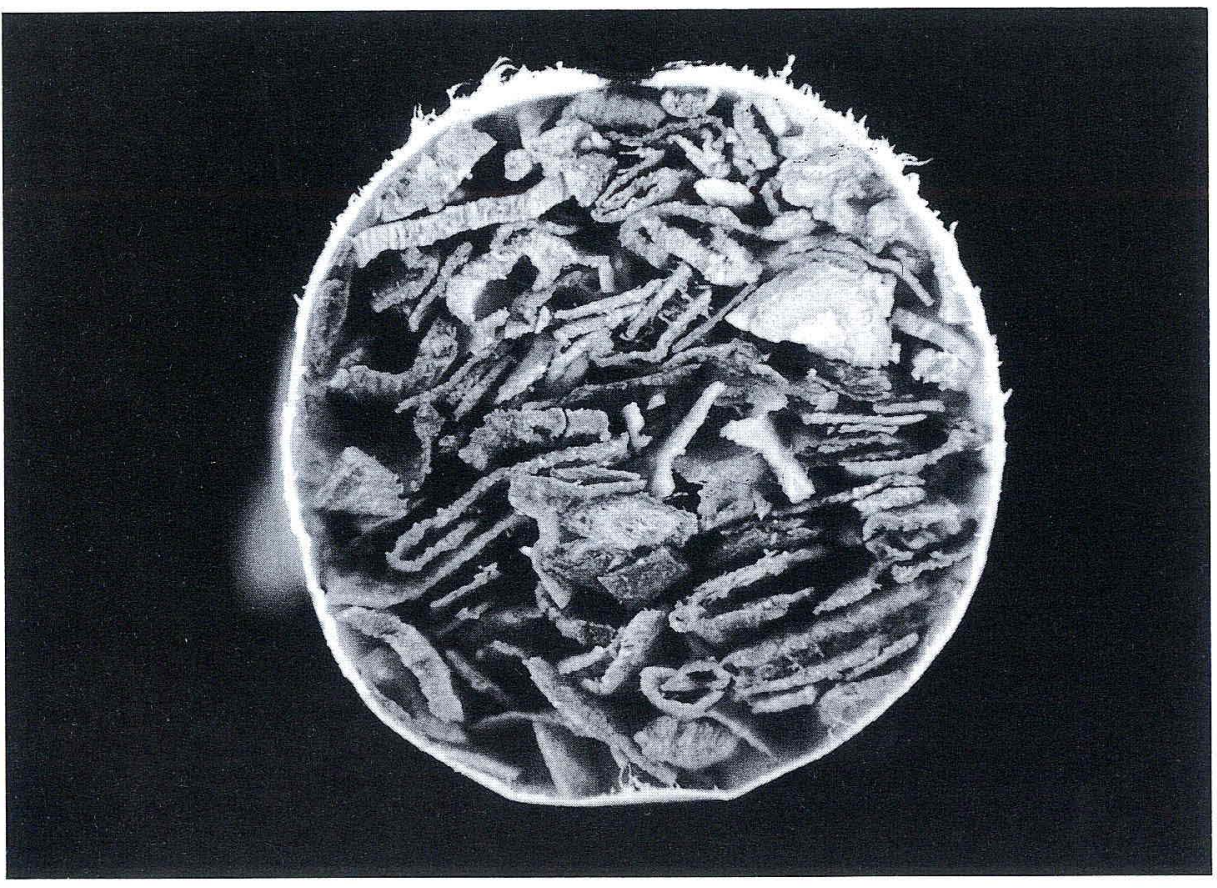

Figure 3b.

Cross-section of Cigarette B.

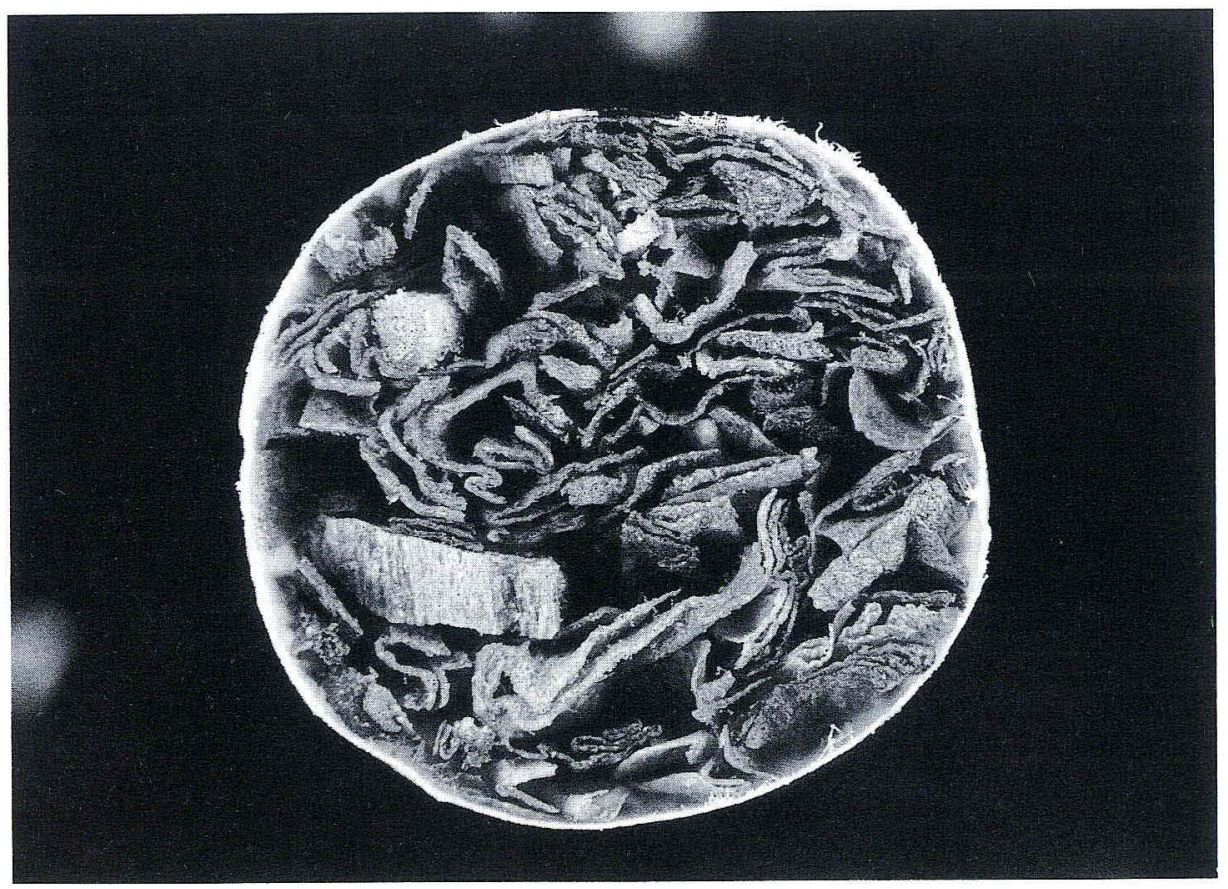




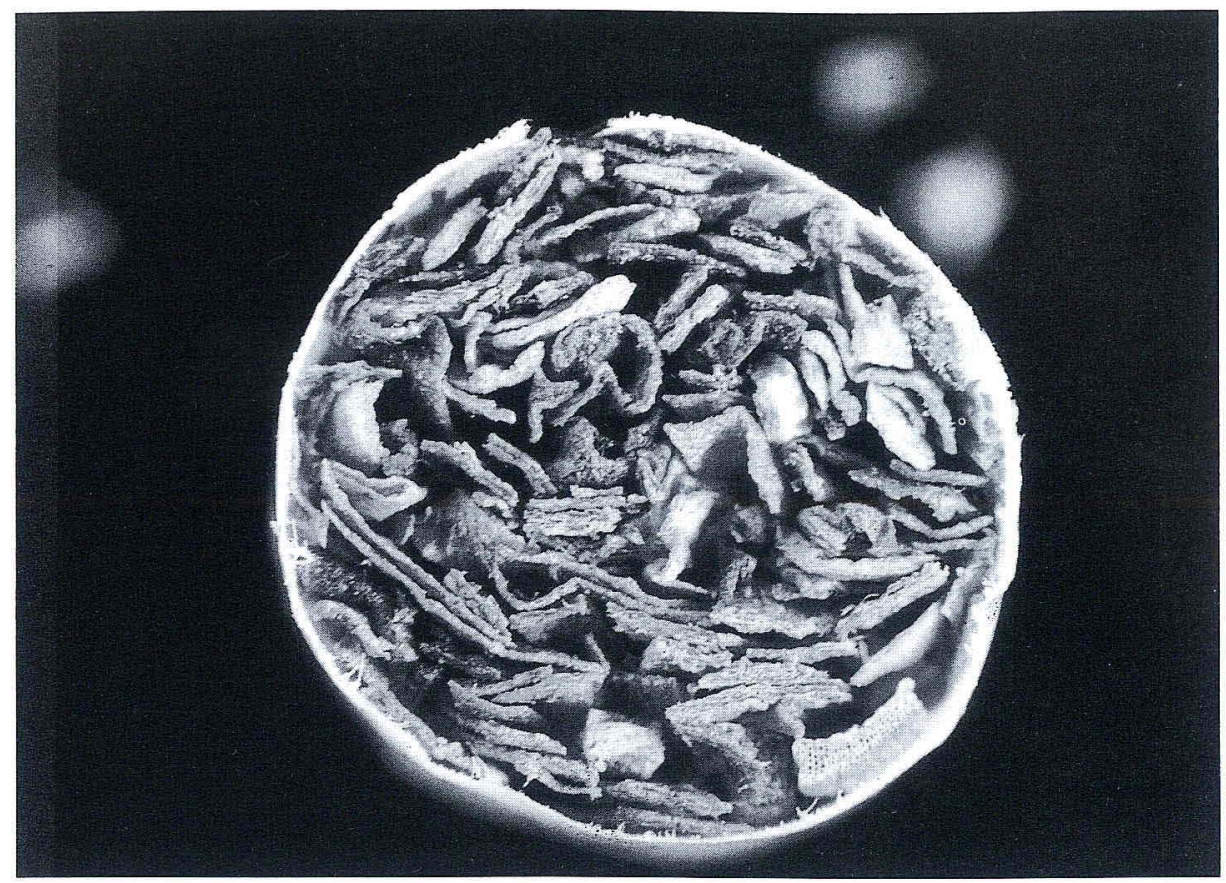

The width and length of the shred cuts are shown on the histograms in Figure 4 and Figure 5, respectively.

The widths of a great number of shred cuts vary between $0.05 \mathrm{~mm}$ and $0.2 \mathrm{~mm}$ which covers the range of all existing types of tobacco leaf thickness.

The lengths of a considerable number of shred cuts are in the $0.75-1.125 \mathrm{~mm}$ range which is most widely used in cutting tobacco leaves. When an $0.8 \mathrm{~mm}$ wide shred is cut at an angle of $45^{\circ}$ to its length, then the cut is $1.13 \mathrm{~mm}$ long.

Figure 6 presents histograms of shred cuts arranged in relation to the angle between the long axis of symmetry of each cut and the seam-line. The largest amount of tobacco shreds oriented almost parallel to the seam-line at angles less than $30^{\circ}$ was calculated in each of the cross-sections and found to be $59.9 \%$ for Cigarette A, 61.6\% for Cigarette B and $59.3 \%$ for Cigarette C. Only a negligible part of tobacco shreds (5.4\% for Cigarette A, $12.8 \%$ for Cigarette B and $14.9 \%$ for Cigarette C) was almost perpendicular (at angles above $60^{\circ}$ ) to the seam-line.

The cross-sections in Figure 3 showed a relatively high coincidence of the histograms of the indices studied with coefficients of concordance such as $W=0.819$ for cutwidths (Figure 4), W $=0.845$ for cut-lengths (Figure 5) and $W=0.877$ for the angles of shred arrangements (Figure 6).

The results obtained from the analyses of cigarette crosssections give grounds for assertion that the cigarette structure is highly characterized by a definite pattern of shred arrangements in accordance with at least two indices:
1. The majority of tobacco shreds are oriented with their lengths along the cigarette lenghts which is the reason why the cross-sections predominate the dimensions defined by the thickness of tobacco leaves and cutwidth.

2. The majority of tobacco shreds have the larger size of their cross-section (cut-width) oriented parallel or almost parallel to the seam-line.

An explanation of shred arrangements in a cigarette structure may by found in the physical processes running during pneumatic formation of the cigarette rod on modern cigarette making machines. The layering of tobacco shreds upon a perforated band moving perpendicularly to the air flow preserves their orientation with their lengths along the cigarette length. The pneumatic pressing of the shreds against the band or against the forming-up stream of tobacco shreds will be the most stable when the largest shred area is in contact with the band or with the shreds already stuck on it. Tobacco shreds form the largest area when lying on cut width. The cigarette seam is formed on the side of the tobacco stream contiguous to the suction band; hence it is only an indication of the pattern-arrangements of the shreds in the cigarette structure. A random arrangement of a smaller part of tobacco shreds is very likely due to a variety of sizes and shapes of real shreds which differ greatly from the idealized notion of three-dimensional shreds.

Encouraged by the discovery of arrangement patterns of tobacco shreds in cigarette structures, we tried to find further evidence in other cigarette properties. We investi- 
Figure 4.

Distribution of tobacco shreds (\%) according to the widths of their cuts $(\mathrm{mm})$.

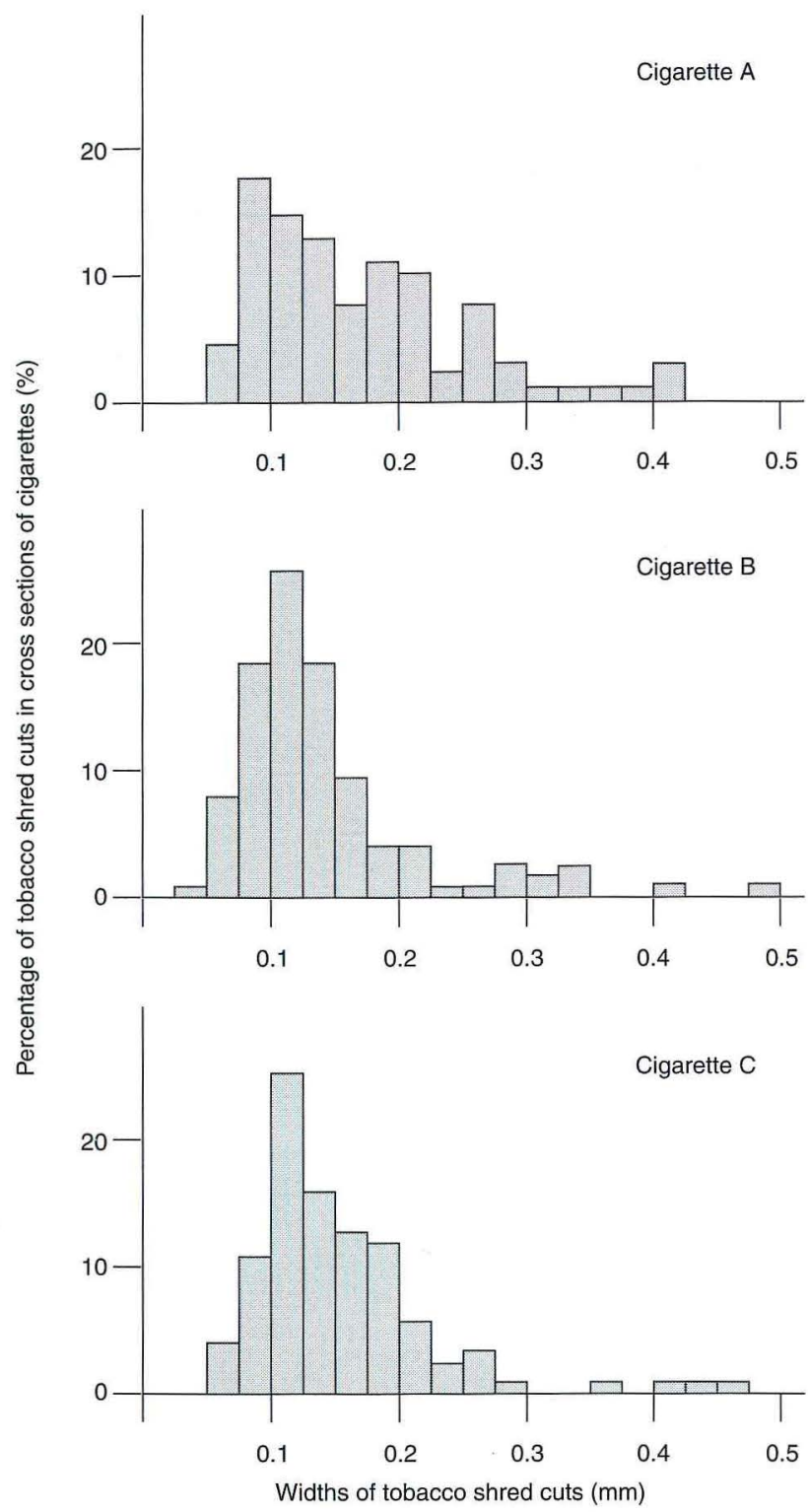

gated the possibility that cigarettes might show different deformation in the two directions, parallel and perpendicular to the seam-line. The measurements of cigarette deformation in different cigarette brands indicated that it was always less in direction parallel to the seam than perpendicular to the seam. This fact is confirmed in Figure 7 obtained from deformation measurements of oriental blend cigarettes made on a Protos 8000 (VE80/SE80, Körber AG, Hamburg, Germany). The cigarettes were first conditioned to $13.9 \%$ tobacco moisture in a Borgwald conditioning chamber $\mathrm{B} 01.04$ at $20{ }^{\circ} \mathrm{C}$ and $63 \%$ relative humidity. They were sorted and divided into groups of ten cigarettes with cigarette mass of $\pm 10 \mathrm{mg}$. The tobacco rod density of a group was calculated $\left(\mathrm{mg} / \mathrm{cm}^{3}\right)$ and its deformation measured with a Borgwald densime-
Figure 5.

Distribution of tobacco shreds (5) according to the lengths of their cuts $(\mathrm{mm})$.

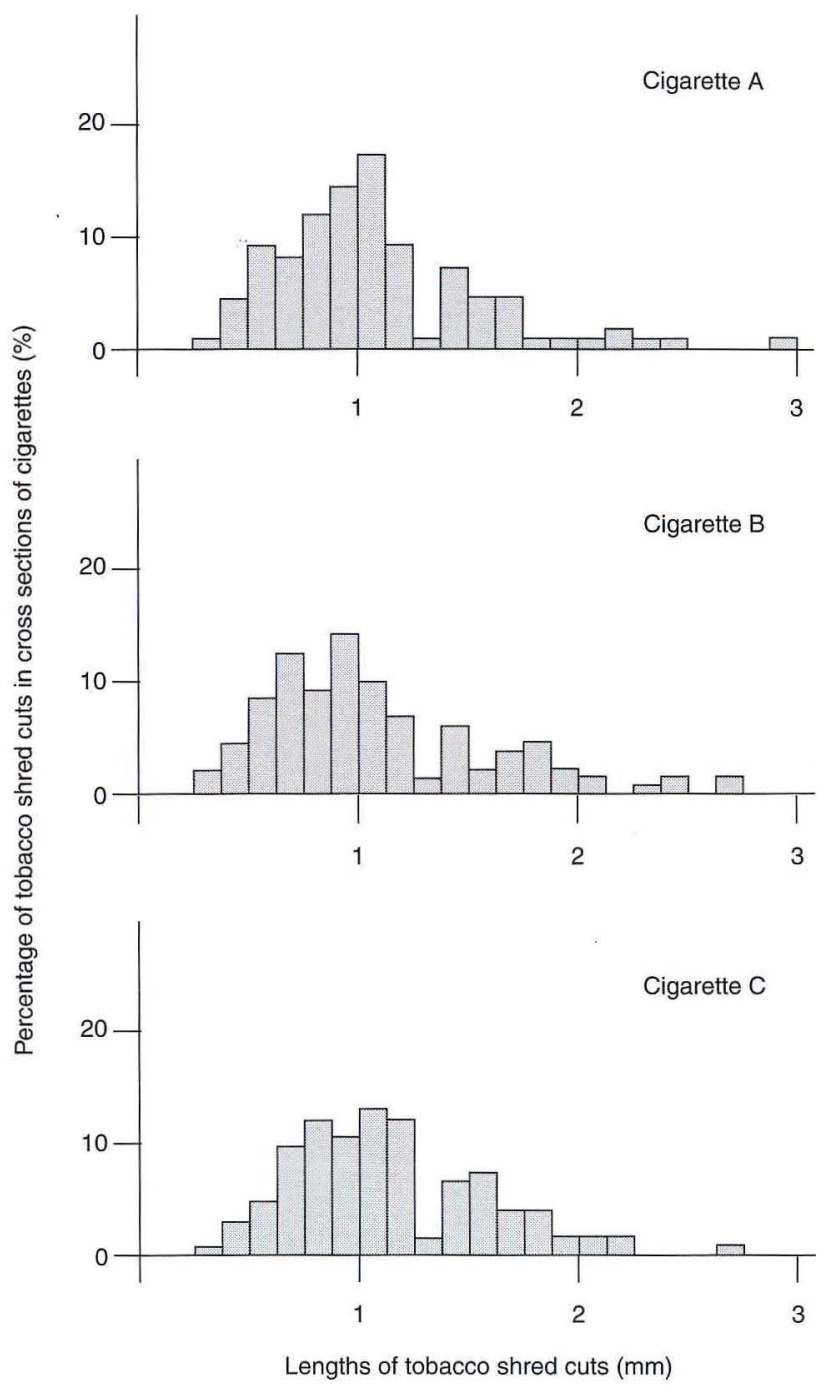

ter DM (H. Burghart, Technische Laborgeräte, Wedel, Germany) both parallel and perpendicular to the seam by arranging and disarranging the cigarettes so that the deformation zones did not overlap during the two measurings.

The linear equations obtained have a high coefficient of correlation and dispersions indicating that the equations are markedly distinguishable from each other. At the same tobacco rod density the sample deformation measured parallel to the seam was approximately $4 \%$ lower than measurements made perpendicular to the seam.

The results of these studies need to be confirmed by further experiments performed with other methods. At this stage we were not able to carry out intensified studies on the arrangement of tobacco shreds in cigarettes produced on different machines although we did detect differences in their deformation resulting from measurements made parallel and perpendicular to the seam. 
Figure 6.

Distribution of tobacco shreds (\%) according to the angles between the long axis of symmetry of their cuts and the seamline.

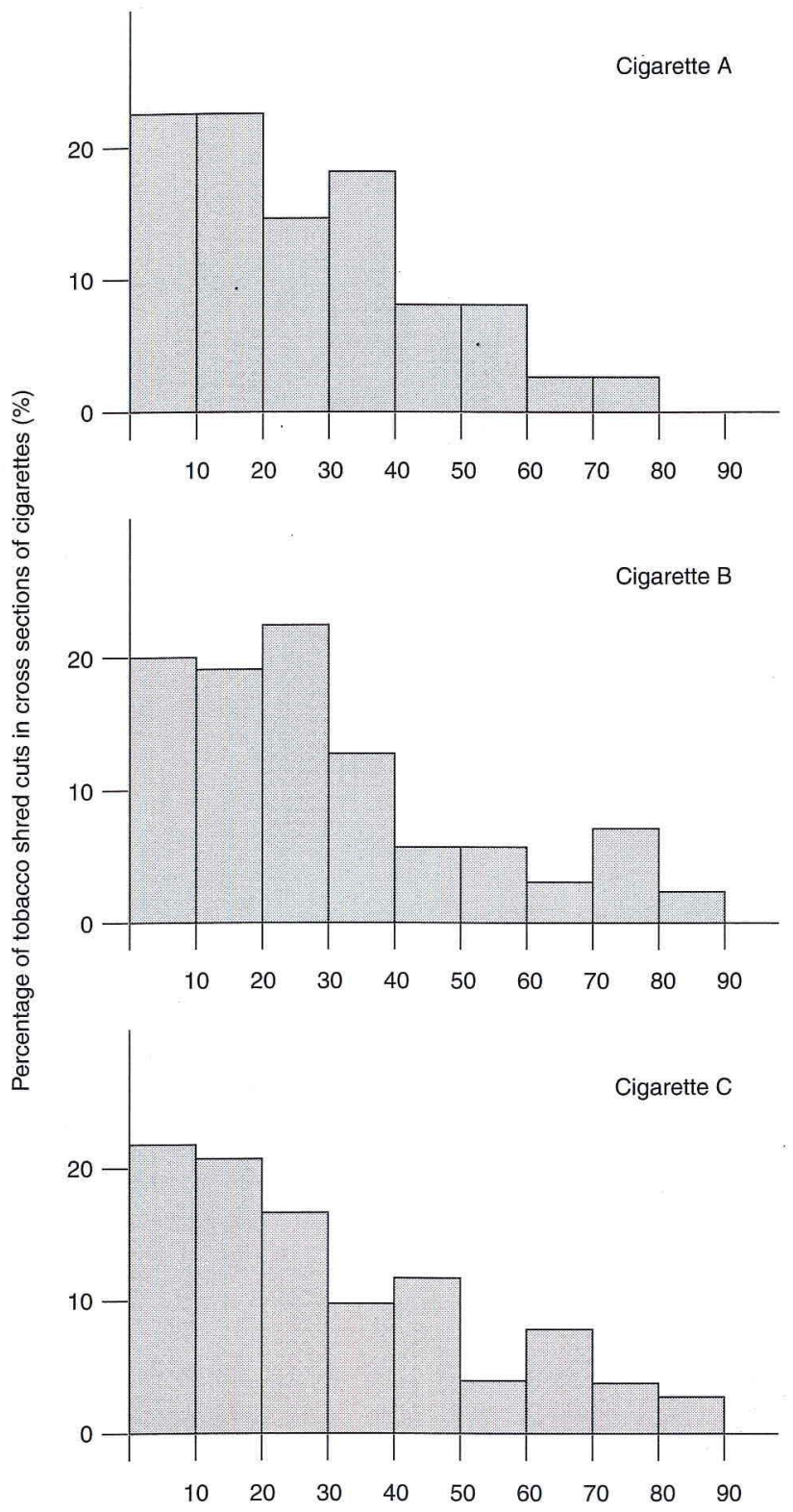

Angle of degree between the long axis of symmetry of tobacco shred cuts and the seam-line.
Figure 7.

Change of cigarette deformation (\%) depending on tobacco rod density $\left(\mathrm{mg} / \mathrm{cm}^{3}\right)$ and position during measurement; a) perpendicular to the seam; b) parallel to the seam.

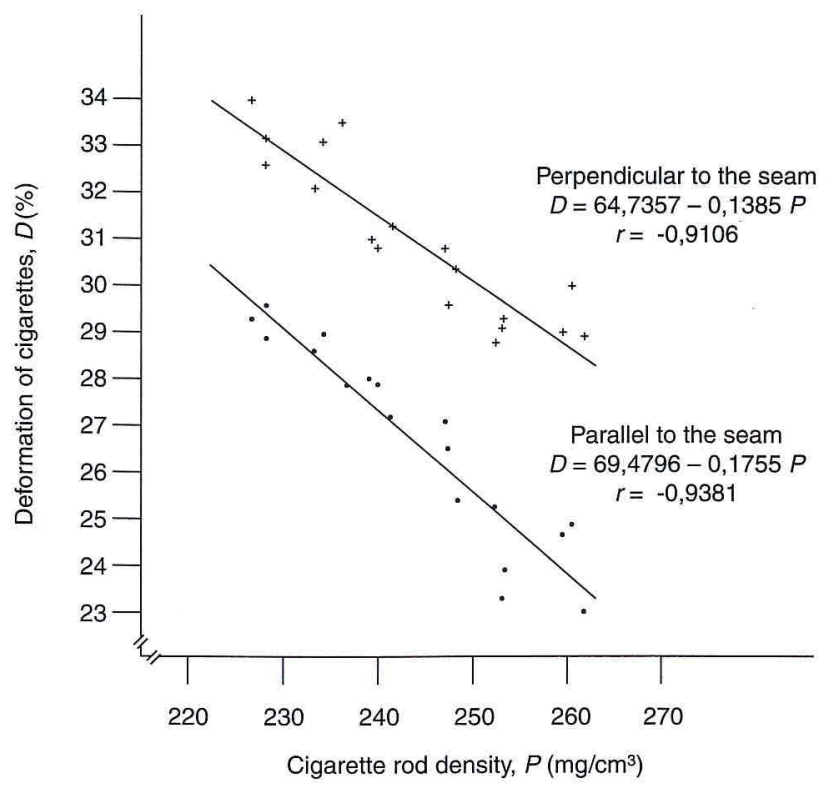

\section{REFERENCES}

1. Goldring, L. S., J. V. Fiore and A. C. Gadziala: X-ray study of cigarette structure; Beitr. Tabakforsch. 7 (1973) 121-137.

2. Brenizer, J. S., M. F. Sulcoski, R. W. Jenkins, Jr., D. D. McRae and R. H. Newman: Observation of density variations in tobacco rods by neutron radiography; Beitr. Tabakforsch. Int. 14 (1987) 21-28.

Authors' address:

Higher Institute of Food and Flavour Industry,

Department of Tobacco and Tobacco

Products Technology,

Maritza Boulevard 26,

4000 Plovdiv, Bulgaria. 